\title{
Indium-Nitrogen Codoped Zinc Oxide Thin Film Deposited by Ultrasonic Spray Pyrolysis on n-(111) Si Substrate: The Effect of Film Thickness
}

\author{
Cheng-Chang Yu, ${ }^{1}$ Wen-How Lan, ${ }^{2}$ and Kai-Feng Huang ${ }^{1}$ \\ ${ }^{1}$ Department of Electrophysics, National Chiao Tung University, Hsinchu 300, Taiwan \\ ${ }^{2}$ Department of Electrical Engineering, National University of Kaohsiung, Kaohsiung 811, Taiwan
}

Correspondence should be addressed to Wen-How Lan; wwhlan@gmail.com

Received 2 October 2013; Revised 27 November 2013; Accepted 12 December 2013; Published 13 February 2014

Academic Editor: Ajay Soni

Copyright (C) 2014 Cheng-Chang Yu et al. This is an open access article distributed under the Creative Commons Attribution License, which permits unrestricted use, distribution, and reproduction in any medium, provided the original work is properly cited.

Indium-nitrogen codoped zinc oxide (INZO) thin films were fabricated by spray pyrolysis deposition technique on $\mathrm{n}$-(111) $\mathrm{Si}$ substrate with different film thicknesses at $450^{\circ} \mathrm{C}$ using a precursor containing zinc acetate, ammonium acetate, and indium nitrate with $1: 3: 0.05$ at.\% concentration. The morphology and structure studies were carried out by scanning electron microscopy (SEM) and X-ray diffraction (XRD). The grain size of the films increased when increasing the film thickness. From XRD spectra, polycrystalline $\mathrm{ZnO}$ structure can be observed and the preferred orientation behavior varied from (002) to (101) as the film thickness increased. The concentration and mobility were investigated by Hall effect measurement. the p-type films with a hole mobility around $3 \mathrm{~cm}^{2} \mathrm{~V}^{-1} \mathrm{~s}^{-1}$ and hole concentration around $3 \times 10^{19} \mathrm{~cm}^{-3}$ can be achieved with film thickness less than $385 \mathrm{~nm}$. The $\mathrm{n}$-type conduction with concentration $1 \times 10^{20} \mathrm{~cm}^{-3}$ is observed for film with thickness $1089 \mathrm{~nm}$. The defect states were characterized by photoluminescence. With temperature-dependent conductivity analysis, acceptor state with activation energy $0.139 \mathrm{eV}$ dominate the $\mathrm{p}$ type conduction for thin INZO film. And the $\mathrm{Zn}$-related shallow donors with activation energy $0.029 \mathrm{eV}$ dominate the n-type conduction for the thick INZO film.

\section{Introduction}

In recent years, the zinc oxide $(\mathrm{ZnO})$ based materials have attracted much attention. Lots of devices have been studied in many fields [1-6]. For unintentionally doped $\mathrm{ZnO}$, it is usually an n-type semiconductor with carriers from the donor levels associated with oxygen vacancies and/or interstitial zinc atoms [7, 8]. High quality n-type $\mathrm{ZnO}$ with $\mathrm{Al}, \mathrm{Ga}$, and In has been reported [9-11]. To achieve p-type $\mathrm{ZnO}$, a popular method is using nitrogen doping as shallow acceptor [12] although the stability of nitrogen in $\mathrm{ZnO}$ is a topic [13]. In the meantime, the nitrogen codoping with certain reactive elements such as $\mathrm{Al}, \mathrm{Ga}$, and In was proposed to enhance the solubility and stability of nitrogen in $\mathrm{ZnO}$ [14-16]. As the nitrogen chemical states varied with the added In element [16], stable and high p-type concentration can be achieved from the In-N codoped ZnO film. Different deposition methods such as sputtering $[17,18]$, sol-gel spin coating [19], and ultrasonic spray pyrolysis (USP) $[16,20]$ were applied. Some studies of the In-N codoped $\mathrm{ZnO}$ about the electrical and optical properties [16, 18, 19], different substrate effect [21], and film postannealing effect [17] were performed. In these studies, all the thickness of the In- $\mathrm{N}$ co-doped $\mathrm{ZnO}$ was less than $0.5 \mathrm{um}$, as $\mathrm{ZnO}$ film properties show a film thicknessdependent behavior [22-24]. Yet, there is less studies about the thicknesses effects for the In- $\mathrm{N}$ codoped $\mathrm{ZnO}$ film. In this work, we prepared the In-N codoped $\mathrm{ZnO}$ thin films by spray pyrolysis with different film thickness and analyzed their morphology, crystalline, and electrical properties. The photoluminescence and activation energies analysis were applied for understanding the conductivity behaviors.

\section{Materials and Methods}

The indium and nitrogen co-doped $\mathrm{ZnO}$ (INZO) thin film was deposited on $\mathrm{n}^{+}$(111) Si substrate at $475^{\circ} \mathrm{C}$ by spray 


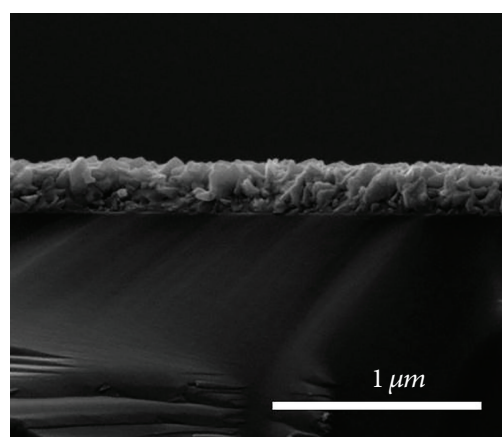

(a)



(d)

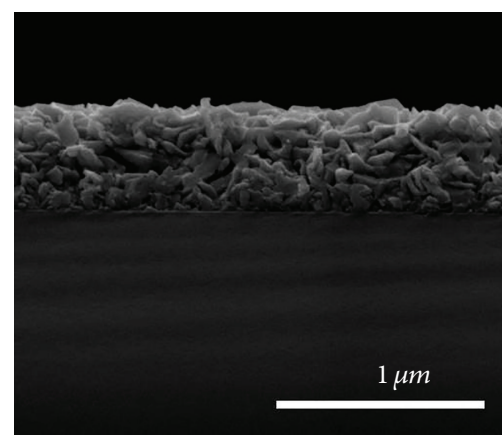

(b)

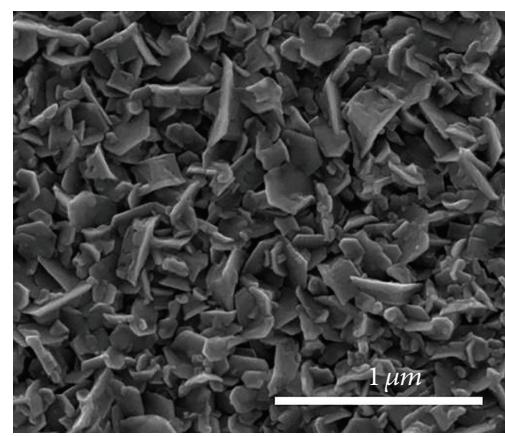

(e)

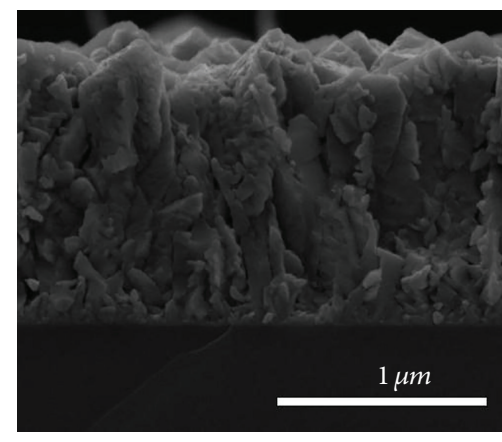

(c)

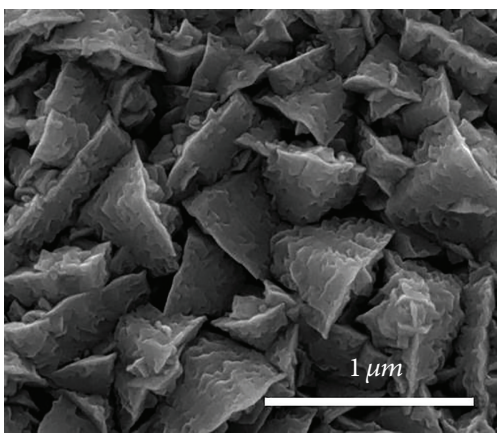

(f)

FIGURE 1: SEM view of cross-section for the ZnO films with different deposited thicknesses: (a) $154 \mathrm{~nm}, \mathrm{~S} 1$, (b) $385 \mathrm{~nm}, \mathrm{~S} 2$, and (c) $1089 \mathrm{~nm}$, S3. The corresponding surface morphologies were shown in (d) S1, (e) S2, and (f) S3, respectively.

pyrolysis [8]. Before deposition, the Si substrate was cleaned by standard cleaning process [25] followed by rinse in $\mathrm{HF}: \mathrm{H}_{2} \mathrm{O}=1: 20$ for $20 \mathrm{~s}$ to remove the oxide layer. The INZO film was formed from the pyrolysis of the precursor of zinc acetate, ammonium acetate, and indium (III) chloride with ratio $1: 3: 0.05$ with different spraying times. The surface morphology and cross-section of the film were studied using scanning electron microscopy (SEM, HITACHI S-4300). The crystalline structure was obtained by X-ray diffraction (XRD, Bruker D8) with $\mathrm{Cu} \mathrm{K}$-alpha radiation. The conductivity was obtained by the van der Pauw four-point method (KEITHLEY 2400) and carrier concentration and mobility were obtained by Hall measurement at the magnetic field strength $0.42 \mathrm{~T}$. The temperature-dependent conductivity properties were characterized with a temperature-controlled stage. The photoluminescence (PL) measurement was carried on MiniPL5.0 system (PHOTON SYSTEMS Inc.) with $\mathrm{NeCu}$ $(248 \mathrm{~nm})$ pulse laser. The depth profile was obtained by secondary ion mass spectrometry (SIMS, Cameca IMS-6f) from MA-tek Inc.

\section{Results and Discussion}

The morphologies of these INZO films were shown in Figure 1. The cross-section was shown in (a) sample S1, (b) sample S2, and (c) sample S3. The film thicknesses measured from the cross-sectional images are $154 \mathrm{~nm}$ (S1), $385 \mathrm{~nm}$ (S2), and $1089 \mathrm{~nm}$ (S3), respectively, as listed in Table 1. The corresponding surface morphologies were shown in (d) S1 (e) S2, and (f) S3, respectively. It is clearly shown that the surface morphologies of the INZO films were considerably affected by film thickness. For thin INZO film as shown in Figure 1(d), the granular structure with some hexagonal plate can be observed. As the film thickness increases by increasing the deposition time, the surface granular structure becomes larger and the cubic-like morphology can be observed in Figure 1(f).

The X-ray diffraction patterns of the INZO films are shown in Figure 2. There are five peaks distinguished in the figure. All these peaks, as labelled in the figure, can be indexed to $\mathrm{ZnO}$ structure.

The three obvious $\mathrm{ZnO}$ peaks were indexed as (100), (002), and (101) planes. For thin INZO film (S1), a dominant (002) peak can be observed in Figure 2(a). The (002) peak intensity decreased with increasing film thickness. The film with thickness $1089 \mathrm{~nm}$ (S3) showed a primary (101) peak. A relative intensity increasing for (110) peak can be observed also as the film thickness increased. The full-width-halfmaximum (FWHM) values of (101) peak were evaluated in Figure 3. The FWHM decreasing with film thickness increasing can be observed. Based on Scherrer's formula, the averaged grain size $D$ for the film can be calculated as [26]

$$
D=\frac{0.94 \lambda}{\beta \cos \theta},
$$

where $\theta$ is the Bragg diffraction angle, $\lambda$ is the wavelength of the incident radiation, and $\beta$ is FWHM of the diffraction ray. The grain size estimated from the (101) peak in the XRD 


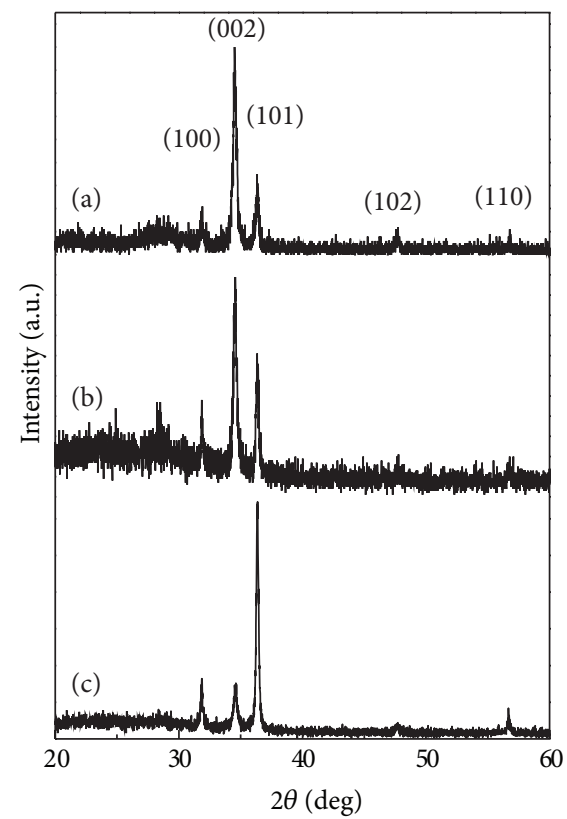

FIgURE 2: XRD spectra for the $\mathrm{ZnO}$ films with different deposited thicknesses: (a) S1, (b) S2, and (c) S3.

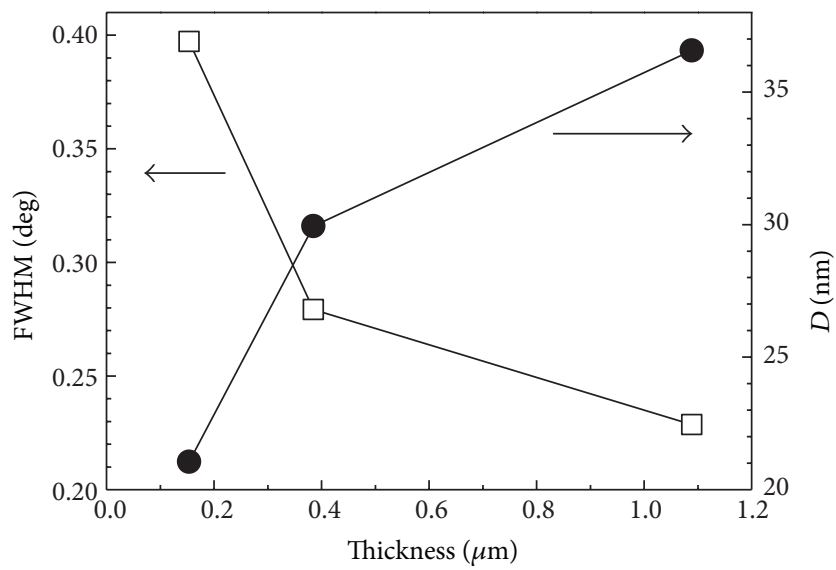

FIGURE 3: The FWHM of the XRD (101) plane and the grain size D.

pattern was shown in Figure 3 also. The grain size increases as the film thickness increases. For thick sample S3, the calculated grain size $36.6 \mathrm{~nm}$ is quite small than the observed cubic size estimated from Figure 1(f). As sectional aligned small grain size formed on the substrate/film interface as shown in Figure 1(c). The calculated grain size shows the average effect on the film.

The texture coefficient $\mathrm{TC}_{(\mathrm{hkl})}$, which represents the texture of the particular (hkl) plane of a film, was well known as [27]

$$
\mathrm{TC}_{(\mathrm{hkl})}=\frac{\operatorname{Im}_{(\mathrm{hkl})}}{\operatorname{Io}_{(\mathrm{hkl})}} \div \frac{1}{N} \sum_{1}^{N} \frac{\operatorname{Im}_{(\mathrm{hkl})}}{\operatorname{Io}_{(\mathrm{hkl})}}
$$

where $\operatorname{Im}_{(\mathrm{hkl})}$ and $\mathrm{Io}_{(\mathrm{hkl})}$ are the measured and referenced peak intensities in JCPDS of the diffraction peak from the
TABLE 1: Texture coefficient $\mathrm{TC}_{(002)}$ and $\mathrm{TC}_{(101)}$ for samples $\mathrm{S} 1$ to $\mathrm{S} 3$.

\begin{tabular}{lccc}
\hline Sample & Thickness $(\mathrm{nm})$ & $\mathrm{TC}_{(002)}$ & $\mathrm{TC}_{(101)}$ \\
\hline S1 & 154 & 2.44 & 0.30 \\
S2 & 385 & 2.07 & 0.52 \\
S3 & 1089 & 0.66 & 1.74 \\
\hline
\end{tabular}

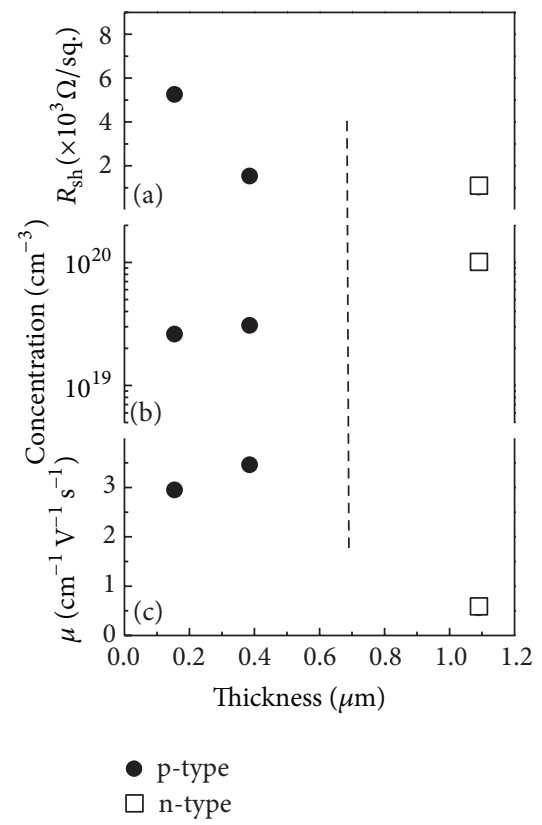

FIgURE 4: The conduction properties of $\mathrm{ZnO}$ thin films with different deposited thicknesses: (a) the sheet resistance $R_{\text {sh }}$, (b) carrier concentration, and (c) Hall mobility $\mu$.

(hkl) plane. The number $N$ is the total number of reflection peaks. The calculated (002) and (101) texture coefficient values $\mathrm{TC}_{(002)}$ and $\mathrm{TC}_{(101)}$ were shown in Table 1 . For thin INZO sample $\mathrm{S} 1$, the $\mathrm{TC}_{(002)}$ has the highest value. The main structure is (002) plane. The dominant (002) plane phenomenon can be observed in several thin $\mathrm{ZnO}$ films $[24,27]$. The preferential orientation of $c$-axis for thin INZO leads to the enhancement of high $\mathrm{TC}_{(002)}$ values. As the film thickness increases, the $\mathrm{TC}_{(002)}$ value decreases and $\mathrm{TC}_{(101)}$ value increases. The preferred texture changed from (002) to (101) with the film thickness increasing. The texture change, which may probably be due to the growth mode variance [24], results in the corresponding surface morphology difference as shown in Figures 1(d)-1(f).

The sheet resistance $\left(R_{\mathrm{sh}}\right)$, concentration, and mobility $(\mu)$ for the INZO films with different thickness are shown in Figures 4(a), 4(b), and 4(c), respectively. To verify the stability of the films, these properties were tested again after one month later and the quantity variation less than $12 \%$ was observed. The sheet resistance decreases as the film thickness increases. From Hall measurement, p-type conduction was characterized for sample S1 and S2 while the n-type conduction was characterized for sample S3. The p-type concentration around $2 \times 10^{19} \mathrm{~cm}^{-3}$, which is near the reported In$\mathrm{N}$ codoped $\mathrm{ZnO}$ film values $[16,19,20]$, reveals the efficient 


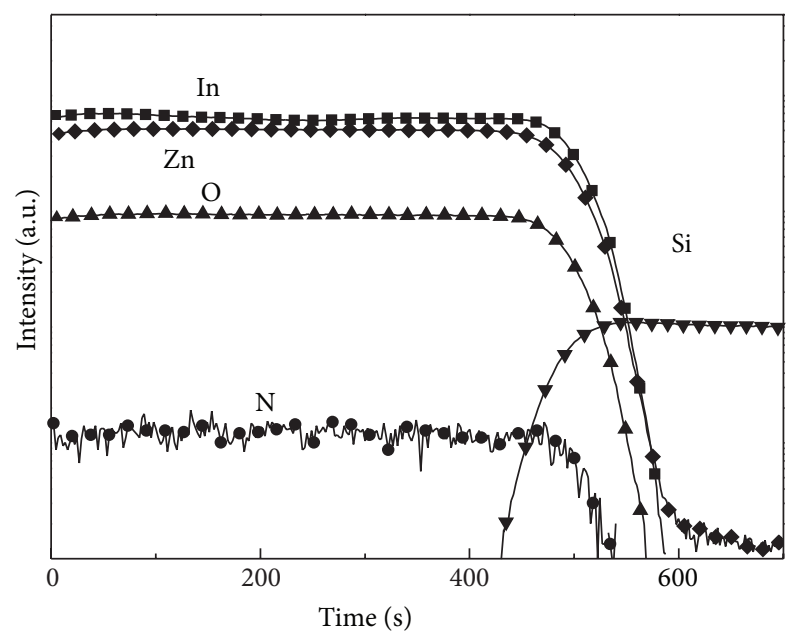

FIGURE 5: SIMS depth profile of sample S3.

nitrogen incorporation in $\mathrm{ZnO}$ film [21]. For the thickest sample S3, the n-type conduction around $1 \times 10^{20} \mathrm{~cm}^{-3}$ can be observed. Compared with sample S2, an enormous change for sample S3 in carrier density from p-type to n-type would require a large carrier compensation mechanism.

In order to clarify the element composition in this INZO film, SIMS depth profile was carried out on sample S3 as shown in Figure 5. The content of In and $\mathrm{N}$ as well as $\mathrm{Zn}$ and O remains constant throughout the whole film was observed. No obvious In and $\mathrm{N}$ composition variation in the film. As the film morphology and preferential orientation change as the film thickness increases, different chemical states may occur with different thickness and dominate the film conduction.

Figure 6 shows the room temperature PL spectra of the three samples. For sample S1, as shown in Figure 6(a), a near band edge emission with peak wavelength $376 \mathrm{~nm}$ can be observed [28-30]. This broadened emission may split to two peaks after Gaussian fitting process [29]. Dominant peak with wavelength $376 \mathrm{~nm}(3.30 \mathrm{eV})$ is attributed to near band edge emission of bound neutral donors $\left(\mathrm{D}^{\circ} \mathrm{X}\right)$. Another emission peak with fitted peak wavelength around $388 \mathrm{~nm}(3.20 \mathrm{eV})$ can be observed in the figure. This peak, which is near the reported peak at $384 \mathrm{~nm}$, may be attributed to the complex defects and arises from the energy transition between donoracceptor pairs (DAP) [29-31]. A small peak around $425 \mathrm{~nm}$ $(2.92 \mathrm{eV})$ can be observed in the figure. Lots of emissions originating from interstitial zinc-related defects were found in this range (415-470 nm) in the p-type Al-N codoped $\mathrm{ZnO}$ film [22]. The emission at $425 \mathrm{~nm}$ may be attributed to the transition related interstitial zinc-related defect $\left(\mathrm{Zn}_{\mathrm{i}}\right)$.

A visible emission with peak wavelength $500 \mathrm{~nm}$ $(2.48 \mathrm{eV})$ can be observed. This peak is attributed to the singly ionized oxygen vacancies $\left[\mathrm{V}_{\mathrm{O}}{ }^{+}\right][29,31,32]$ or zinc interstitial [33] and can be observed in the p-type $\mathrm{N}$ doped $\mathrm{ZnO}$ [33].

For sample S2, similar emission peaks can be observed. The increasing of emission intensity ratio of $\mathrm{D}^{\circ} \mathrm{X} / \mathrm{DAP}$ can be observed. Besides, broadened emission with peak wavelength around $520 \mathrm{~nm}(2.38 \mathrm{eV})$ can be observed. The emission with
TABLE 2: The activation energies $E_{A}$ for different samples.

\begin{tabular}{lc}
\hline Sample & Activation energy $E_{A}(\mathrm{eV})$ \\
\hline S1 & $0.144(T=300 \mathrm{~K}-350 \mathrm{~K})$ \\
S2 & $0.139(T=300 \mathrm{~K}-390 \mathrm{~K})$ \\
S3 & $0.029(T=300 \mathrm{~K}-390 \mathrm{~K})$ \\
\hline
\end{tabular}

peak wavelength $498 \mathrm{~nm}$ as seen in sample S1 may be inclosed in this broadened emission band. This green emission which can be observed in many $\mathrm{ZnO}$ film $[28,29]$ is attributed to the transition of conduction band to the oxygen antisite state $\left[\mathrm{O}_{\mathrm{Zn}}\right]$ [28], radiative optical transition in interstitial oxygen $\left[\mathrm{O}_{\mathrm{i}}\right]$ [29], or the zinc vacancy $\left[\mathrm{V}_{\mathrm{Zn}}\right]$-related defect transition $[28,32]$.

For sample S3, with film thickness increasing, the emission intensity ratio of $\mathrm{D}^{\circ} \mathrm{X} / \mathrm{DAP}$ increases more and the fitted bandwidth for DAP decreases. An emission with peak wavelength $415 \mathrm{~nm}(2.99 \mathrm{eV})$ can be observed. This emission, which still lies in the spectral range as mentioned (415$470 \mathrm{~nm}$ ), was attributed to certain $\mathrm{Zn}_{\mathrm{i}}$ defects [22]. Compare with sample S2, the appearance of the peak reveals that some certain $\mathrm{Zn}_{\mathrm{i}}$ defects were enhanced for thick INZO films. As the ionization energy for this n-type defect $\mathrm{Zn}_{\mathrm{i}}$ is only $50 \mathrm{meV}$ [34], high electron concentration may come from such defect state at room temperature.

For further understanding the carrier conduction mechanism, temperature-dependent conductivity measurement was carried out for all samples. For the semiconductor film with grain structure, the film conductivity may be affected by the grain size and electronic mean free path $[35,36]$. To estimate the effect of grain boundary scattering, the mean free path $l$ for carriers in the film can be calculated as [35]

$$
l=\left(\frac{h}{2 e}\right)\left(\frac{3 n}{\pi}\right)^{1 / 3} \mu,
$$

where $n$ and $\mu$ are the carrier concentration and mobility, respectively. The calculated values at room temperature are $17 \mathrm{~nm}$ (S1), $22 \mathrm{~nm}$ (S2), and $5 \mathrm{~nm}$ (S3), respectively. These results all are less than the crystalline grain size $D$, suggesting that the contribution from the grain boundary scattering mechanism at room temperature can be neglected.

Figure 7 shows the conductivity measured with different temperatures for samples S1 to S3. For semiconductor with electrical conductivity dominated by the activation of doping level, the relationship between electrical conductivity $\sigma$ and the measurement temperature $T$ is given by [26]

$$
\sigma=\sigma_{0} \exp \left(-\frac{E_{A}}{k T}\right)
$$

where $\sigma_{0}$ is the preexponential factor, $k$ is the Boltzmann constant, and $E_{A}$ is the activation energy. The calculated $E_{A}$ values were listed in Table 2.

For S1, two different regions in different temperature ranges can be observed. This suggests the presence of two different sorts of conduction mechanism in sample S1. Activation energy values for region I ( $300 \mathrm{~K}$ to $350 \mathrm{~K}$ ) and II (360 to $390 \mathrm{~K}$ ) were calculate, respectively, from the linear portions. 




(a)

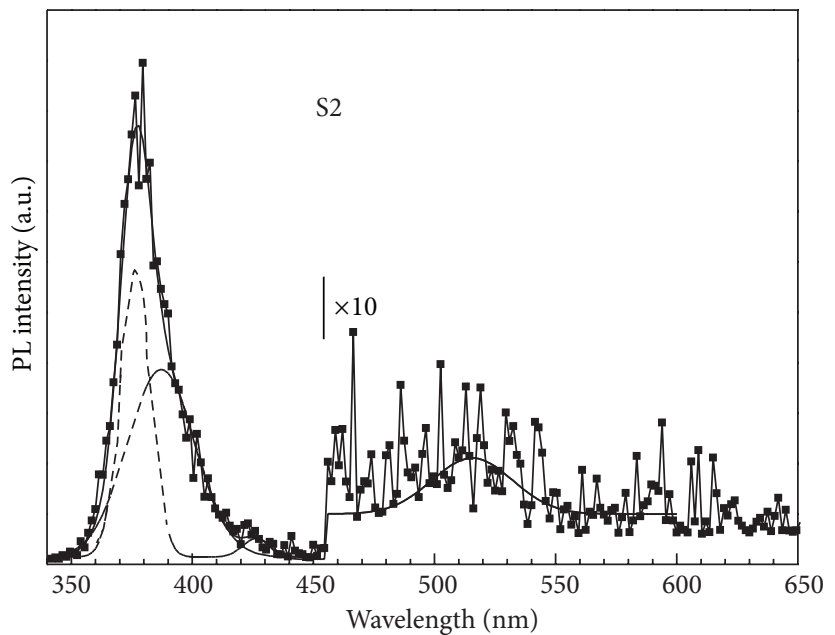

(b)

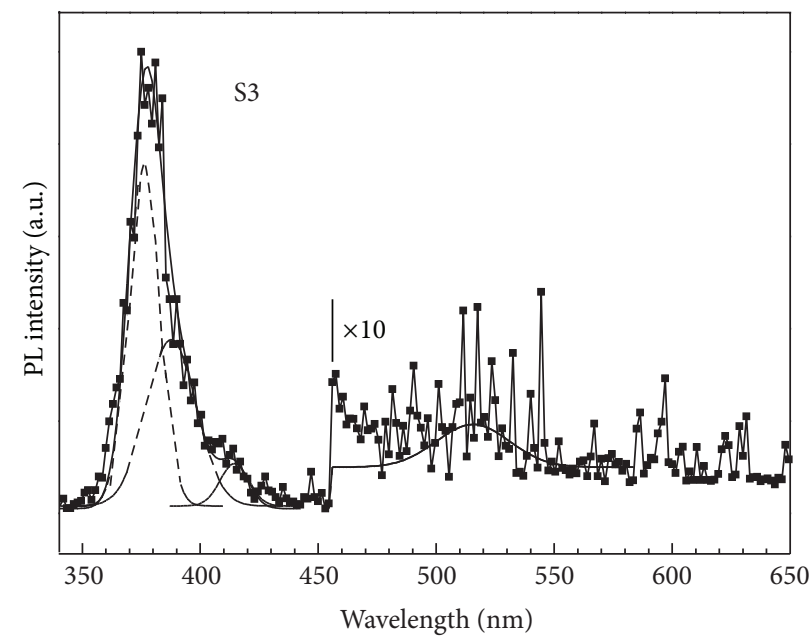

(c)

FIGURE 6: Room temperature PL spectra for samples (a) S1, (b) S2, and (c) S3. The Gaussian fitting curves at different spectra ranges were shown.

The obtained $E_{A}$ values are $0.144 \mathrm{eV}$ and $0.491 \mathrm{eV}$, respectively. For region $\mathrm{I}$, this activation energy value is quite near the reported $0.135-0.14 \mathrm{eV}$ for the $\mathrm{N}$-doped $\mathrm{ZnO}[37,38]$ and thus was assigned as the defect complex of O-site $\mathrm{N}-\mathrm{Zn}$ vacancy $\left(\mathrm{N}_{\mathrm{O}}-\mathrm{V}_{\mathrm{Zn}}\right)$ [39]. The shallow acceptor coming from this complex takes p-type concentration contribution in region $\mathrm{I}$.

In region II, the obtained active energy value is relatively small compared with the band gap energy of $\mathrm{ZnO}$. Besides, the activation energy calculated from two adjacent points for $\mathrm{S} 1$ in region II increases with temperature. This behavior and energy value, which have been observed for other $\mathrm{ZnO}$ based films [26], were corresponding to the grain boundary related scattering. With temperature increasing, the conductivity increases as the increasing of carrier concentration. For S1, the conductivity enhancement of 2.4 times can be observed as the temperature increases from room temperature to $87^{\circ} \mathrm{C}$ $\left(1000 / T=2.78 \mathrm{~K}^{-1}\right)$. If the concentration increases 2.4 times also with a little mobility drop, the mean free path at $87^{\circ} \mathrm{C}$ is then estimated to be $26 \mathrm{~nm}$. In this case, the mean free path of carriers in sample S1 in region II is larger than the grain size $D$; the grain boundary related scattering cannot be neglected. In this case, the conductivity $\sigma$ controlled by grain boundary can be described as $[40,41]$

$$
\sigma=\frac{q^{2} N D}{\sqrt{2 \pi m^{*} k T}} \exp \left(-\frac{E_{B}}{k T}\right)
$$

where $N$ is the carrier concentration, $D$ is the grain size, $m^{*}$ is the effective mass, and $E_{B}$ is the mean barrier height across the grain boundary. The inset in Figure 7 shows the plot of $\ln \left(\sigma T^{1 / 2}\right)$ versus $1000 / T$ for $\mathrm{S} 1$ in region II. The barrier height $E_{B}$ of the film was found to be $0.51 \mathrm{eV}$. The conductivity for S1 in temperature range II $(360 \mathrm{~K}-390 \mathrm{~K})$ is controlled by the grain boundaries. The disordered grain boundaries with trapping state will capture carriers. The conductivity thus is controlled by the transition ability for carriers passing 


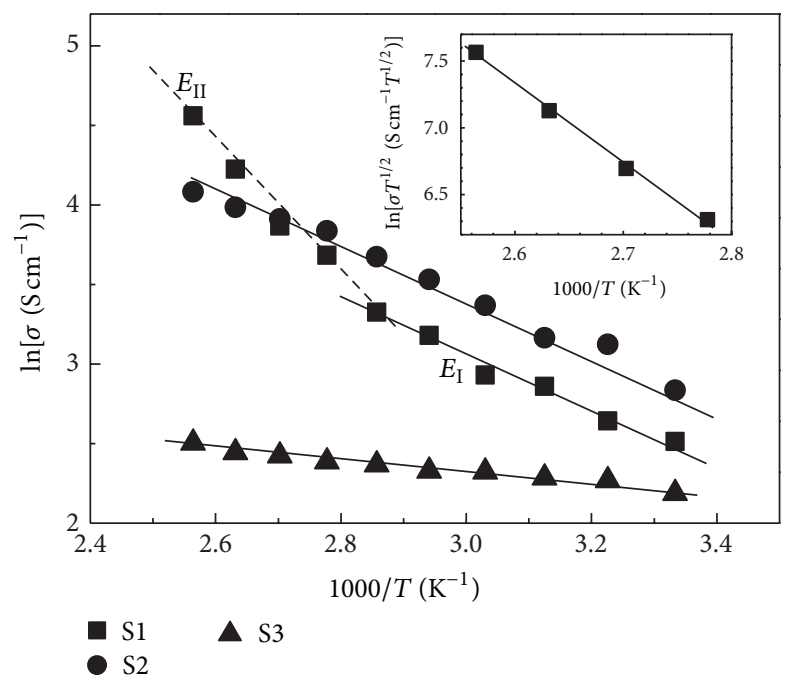

FIGURE 7: Conductivity measured at different temperatures for the $\mathrm{ZnO}$ films with different deposited thicknesses.

through the barrier and the conduction mechanism is grain boundary scattering.

For sample S2, a linear relation can be observed in Figure 7. The extracted activation energy by (4) is $0.139 \mathrm{eV}$. This value, which is near the previous $0.144 \mathrm{eV}$, reveals the same conduction mechanism for S2 and S1 in region I, which is dominant by the acceptor complex of $\mathrm{N}_{\mathrm{O}}-\mathrm{V}_{\mathrm{Zn}}$.

For the thickest sample S3, a linear relation can be observed in Figure 7 also. The extracted activation energy by (3) is $0.029 \mathrm{eV}$. There is no nitrogen-related state associated with such low activation energy [37-39]. This activation value may correspond to the origin donor level for the indium doped $\mathrm{ZnO}(0.026 \mathrm{eV})$ [26] or the interstitial $\mathrm{Zn}_{\mathrm{i}}$-related complex $(0.031 \mathrm{eV})$ [40]. This shallow donor level, which caused the measured n-type conduction also, dominates the conduction mechanism for the thickest sample S3.

For thick INZO film, the grain size becomes bigger. The effect of hole accumulation in Si substrate interface [42] reduces with the increasing of film thickness. Besides, effect of grain boundary becomes less and the preferential orientation changes also with the increasing of film thickness. The $\mathrm{p}$ type conduction enhanced by grain boundary related states becomes less $[42,43]$. Both reduce the acceptor concentration and the shallow donor state corresponding to the interstitial $\mathrm{Zn}_{\mathrm{i}}$-related complex which has dominant effect on the conduction mechanism for this thick INZO film.

\section{Conclusion}

In conclusion, INZO thin films were prepared by spray pyrolysis, and the effects of film thickness on structure and surface morphology were studied. The thin INZO films showed preferential orientation along the (002) plane with tiny flake morphology. For INZO film with thickness $1089 \mathrm{~nm}$, the preferential orientation was shifted to (101) plane with cubiclike morphology. The conduction type shows p-type for thin film and changes to n-type for the thick film after the Hall measurement. From the activation analysis coming from the temperature-dependent conductivity measurement, the nitrogen-related acceptor state and the grain boundary scattering dominate the $\mathrm{p}$-type conduction for thin film. The change from $\mathrm{p}$-type to n-type conduction for thick INZO film was characterized by the photoluminescence and activation energy analysis as the appearance of $\mathrm{Zn}$-related shallow donors.

\section{Conflict of Interests}

The authors declare that there is no conflict of interests regarding the publication of this paper.

\section{References}

[1] J. Hüpkes, B. Rech, O. Kluth et al., "Surface textured MF-sputtered $\mathrm{ZnO}$ films for microcrystalline silicon-based thin-film solar cells," Solar Energy Materials \& Solar Cells, vol. 90, no. 1819, pp. 3054-3060, 2006.

[2] W.-C. Shih and R.-C. Huang, "Fabrication of high frequency $\mathrm{ZnO}$ thin film SAW devices on silicon substrate with a diamond-like carbon buffer layer using RF magnetron sputtering," Vacuum, vol. 83, no. 3, pp. 675-678, 2008.

[3] S. K. Jha, O. Kutsay, I. Bello, and S. T. Lee, "ZnO nanorod based low turn-on voltage LEDs with wide electroluminescence spectra," Journal of Luminescence, vol. 133, pp. 222-225, 2013.

[4] H. S. Al-Salman and M. J. Abdullah, "Effect of Co-doping on the structure and optical properties of $\mathrm{ZnO}$ nanostructure prepared by RF-magnetron sputtering," Superlattices and Microstructures, vol. 60, pp. 349-357, 2013.

[5] L. Luo, L. Gong, Y. F. Liu et al., "Enhanced ultraviolet lasing from europium-doped zinc oxide nanocrystals," Optical Materials, vol. 32, no. 9, pp. 1066-1070, 2010.

[6] G. Z. Xing, D. D. Wang, B. Yao, A. Q. L. F. Nien, and Y. S. Yan, "Structural characteristics, low threshold ultraviolet lasing and ultrafast carrier dynamics in high crystalline $\mathrm{ZnO}$ nanowire arrays," Chemical Physics Letters, vol. 515, pp. 132-136, 2011.

[7] J. C. Simpson and J. F. Cordaro, "Characterization of deep levels in zinc oxide," Journal of Applied Physics, vol. 63, no. 5, pp. 1781$1783,1988$.

[8] C. C. Yu, Y. T. Hsu, S. Y. Lee et al., "Effects of doping ratio and thermal annealing on structural and electrical properties of boron-doped $\mathrm{ZnO}$ thin films by spray pyrolysis," Japanese Journal of Applied Physics, vol. 52, Article ID 065502, 5 pages, 2013.

[9] P. Nunes, E. Fortunato, P. Tonello, F. Braz Fernandes, P. Vilarinho, and R. Martins, "Effect of different dopant elements on the properties of $\mathrm{ZnO}$ thin films," Vacuum, vol. 64, no. 3-4, pp. 281-285, 2002.

[10] Y. Morinaga, K. Sakuragi, N. Fujimura, and T. Ito, "Effect of Ce doping on the growth of $\mathrm{ZnO}$ thin films," Journal of Crystal Growth, vol. 174, no. 1-4, pp. 691-695, 1997.

[11] A. Tiburcio-Silver, J. C. Joubert, and M. Labeau, "Études sur la croissance, la structure et la composition de couches minces de $\mathrm{ZnO}$ et $\mathrm{ZnO}$ dopé a l'indium, obtenues par procédé pyrosol," Thin Solid Films, vol. 197, no. 1-2, pp. 195-214, 1991.

[12] A. Kobayashi, O. G. Sankey, and J. D. Dow, “Deep energy levels of defects in the wurtzite semiconductors AIN, CdS, CdSe, ZnS, and ZnO," Physical Review B, vol. 28, pp. 946-951, 1983. 
[13] X. Chen, Z. Zhang, B. Yao et al., "Effect of compressive stress on stability of N-doped p-type ZnO," Applied Physics Letters, vol. 99, no. 9, Article ID 091908, 3 pages, 2011.

[14] T. Yamamoto and H. Katayama-Yoshida, "Physics and control of valence states in $\mathrm{ZnO}$ by codoping method," Physica B, vol. 302-303, pp. 155-162, 2001.

[15] M. Joseph, H. Tabata, H. Saeki, K. Ueda, and T. Kawai, "Fabrication of the low-resistive p-type $\mathrm{ZnO}$ by codoping method," Physica B, vol. 302-303, pp. 140-148, 2001.

[16] J. M. Bian, X. M. Li, X. D. Gao, W. D. Yu, and L. D. Chen, "Deposition and electrical properties of N-In codoped p-type $\mathrm{ZnO}$ films by ultrasonic spray pyrolysis," Applied Physics Letters, vol. 84, no. 4, pp. 541-543, 2004.

[17] N. Yuan, L. Fan, J. Li, and X. Wang, "Post-annealing influence on properties of $\mathrm{N}$-In codoped $\mathrm{ZnO}$ thin films prepared by ion beam enhanced deposition method," Applied Surface Science, vol. 253, no. 11, pp. 4990-4993, 2007.

[18] N. Yuan, J. Li, L. Fan, X. Wang, and Y. Zhou, "Structure, electrical and optical properties of N-In codoped $\mathrm{ZnO}$ thin films prepared by ion-beam enhanced deposition method," Journal of Crystal Growth, vol. 290, no. 1, pp. 156-160, 2006.

[19] Y. Cao, L. Miao, S. Tanemura, M. Tanemura, Y. Kuno, and Y. Hayashi, "Low resistivity $\mathrm{p}-\mathrm{ZnO}$ films fabricated by sol-gel spin coating," Applied Physics Letters, vol. 88, no. 25, Article ID 251116, 3 pages, 2006.

[20] J. Bian, X. Li, L. Chen, and Q. Yao, "Properties of undoped ntype $\mathrm{ZnO}$ film and $\mathrm{N}$-In codoped p-type $\mathrm{ZnO}$ film deposited by ultrasonic spray pyrolysis," Chemical Physics Letters, vol. 393, no. 1-3, pp. 256-259, 2004.

[21] L. L. Chen, J. G. Lu, Z. Z. Ye et al., "p-type behavior in In-N codoped ZnO thin films," Applied Physics Letters, vol. 87, Article ID 252106, 3 pages, 2005.

[22] A. Zhong, J. Tana, H. Huanga, S. Chena, M. Wanga, and S. Xua, "Thickness effect on the evolution of morphology and optical properties of ZnO films," Applied Surface Science, vol. 257, no. 9, pp. 4051-4055, 2011.

[23] Y. H. Kang, J.-H. Choi, T. I. Lee, W. Lee, and J.-M. Myoung, "Thickness dependence of the resistive switching behavior of nonvolatile memory device structures based on undoped $\mathrm{ZnO}$ films," Solid State Communications, vol. 151, no. 23, pp. 17391742, 2011.

[24] L. Xu, X. Li, Y. Chen, and F. Xu, "Structural and optical properties of $\mathrm{ZnO}$ thin films prepared by sol-gel method with different thickness," Applied Surface Science, vol. 257, no. 9, pp. 4031-4037, 2011.

[25] W. Kern, "The evolution of silicon wafer cleaning technology," Journal of the Electrochemical Society, vol. 137, no. 6, pp. 18871892, 1990.

[26] M. Benhaliliba, C. E. Benouis, M. S. Aida, F. Yakuphanoglu, and A. Sanchez Juarez, "Indium and aluminium-doped $\mathrm{ZnO}$ thin films deposited onto FTO substrates: nanostructure, optical, photoluminescence and electrical properties," Journal of Sol-Gel Science and Technology, vol. 55, no. 3, pp. 335-342, 2010.

[27] S. Ilican, Y. Caglar, M. Caglar, and F. Yakuphanoglu, "Electrical conductivity, optical and structural properties of indium-doped $\mathrm{ZnO}$ nanofiber thin film deposited by spray pyrolysis method," Physica E, vol. 35, no. 1, pp. 131-138, 2006.

[28] A. S. Gadallah and M. M. E. Nahass, "Structural, optical constants and photoluminescence of $\mathrm{ZnO}$ thin films grown by SolGel spin coating," Advances in Condensed Matter Physics, vol. 2013, Article ID 234546, 11 pages, 2013.
[29] A. C. Rastogi, S. B. Desu, P. Bhattacharya, and R. S. Katiyar, "Effect of strain gradation on luminescence and electronic properties of pulsed laser deposited zinc oxide thin films," Journal of Electroceramics, vol. 13, no. 1-3, pp. 345-352, 2004.

[30] C. V. Manzano, D. Alegre, O. C. Calero, B. Alen, and M. S. M. Gonzalez, "Synthesis and luminescence properties of electrodeposited ZnO films," Journal of Applied Physics, vol. 110, Article ID 043538, 3 pages, 2011.

[31] J. C. Fan, K. M. Sreekanth, Z. Xie, S. L. Chang, and K. V. Rao, "ptype $\mathrm{ZnO}$ materials: theory, growth, properties and devices," Progress in Materials Science, vol. 58, no. 6, pp. 847-985, 2013.

[32] S. Golshahi, S. M. Rozati, R. Martins, and E. Fortunato, "p-type $\mathrm{ZnO}$ thin film deposited by spray pyrolysis technique: the effect of solution concentration," Thin Solid Films, vol. 518, no. 4, pp. 1149-1152, 2009.

[33] J. C. Sun, H. W. Liang, J. Z. Zhao et al., "Ultraviolet electroluminescence from $\mathrm{n}-\mathrm{ZnO}: \mathrm{Ga} / \mathrm{p}-\mathrm{ZnO}: \mathrm{N}$ homojunction device on sapphire substrate with p-type $\mathrm{ZnO}: \mathrm{N}$ layer formed by annealing in $\mathrm{N}_{2} \mathrm{O}$ plasma ambient," Chemical Physics Letters, vol. 460, no. 4-6, pp. 548-551, 2008.

[34] L. Schmidt-Mende and J. L. MacManus-Driscoll, " $\mathrm{ZnO}$-nanostructures, defects, and devices," Materials Today, vol. 10, no. 5, pp. 40-48, 2007.

[35] M. Chen, Z. L. Pei, X. Wang et al., "Intrinsic limit of electrical properties of transparent conductive oxide films," Journal of Physics D, vol. 33, no. 20, pp. 2538-2541, 2000.

[36] L. L. Chen, Z. Z. Ye, J. G. Lu et al., "Co-doping effects and electrical transport in In-N doped zinc oxide," Chemical Physics Letters, vol. 432, no. 1-3, pp. 352-355, 2006.

[37] D. C. Look, "Electrical and optical properties of p-type ZnO," Semiconductor Science and Technology, vol. 20, no. 4, pp. 55-61, 2005.

[38] H. B. Ye, J. F. Kong, W. Z. Shen, J. L. Zhao, and X. M. Li, “Temperature-dependent photoluminescence of undoped, N-doped and N-In codoped ZnO thin films," Journal of Physics D, vol. 40, no. 18, pp. 5588-5591, 2007.

[39] L. Liu, J. Xu, D. Wang et al., "p-type conductivity in N-doped $\mathrm{ZnO}$ : the role of the $\mathrm{N}_{\mathrm{Zn}}-\mathrm{V}_{\mathrm{O}}$ complex," Physical Review Letters, vol. 108, no. 21, Article ID 215501, 5 pages, 2012.

[40] Ü. Özgür, Y. I. Alivov, C. Liu et al., "A comprehensive review of $\mathrm{ZnO}$ materials and devices," Journal of Applied Physics, vol. 98, Article ID 041301, 4 pages, 2005.

[41] N. C. C. Lu, L. Gerzberg, C. Y. Lu, and J. D. Meindl, "Modeling and optimization of monolithic polycrystalline silicon resistors," IEEE Transactions on Electron Devices, vol. 28, no. 7, pp. 818-830, 1981.

[42] J. L. Zhao, X. M. Li, A. Krtschil et al., "Ultraviolet and visible electroluminescence from $\mathrm{n}-\mathrm{ZnO} / \mathrm{SiO}_{x} /(n, p)$-Si heterostructured light-emitting diodes," Applied Physics Letters, vol. 90, Article ID 062118, 3 pages, 2007.

[43] B. Wang, J. Min, Y. Zhao, W. Sang, and C. W. Gao, “The grain boundary related p-type conductivity in $\mathrm{ZnO}$ films prepared by ultrasonic spray pyrolysis," Applied Physics Letters, vol. 94, Article ID 192101, 3 pages, 2009. 

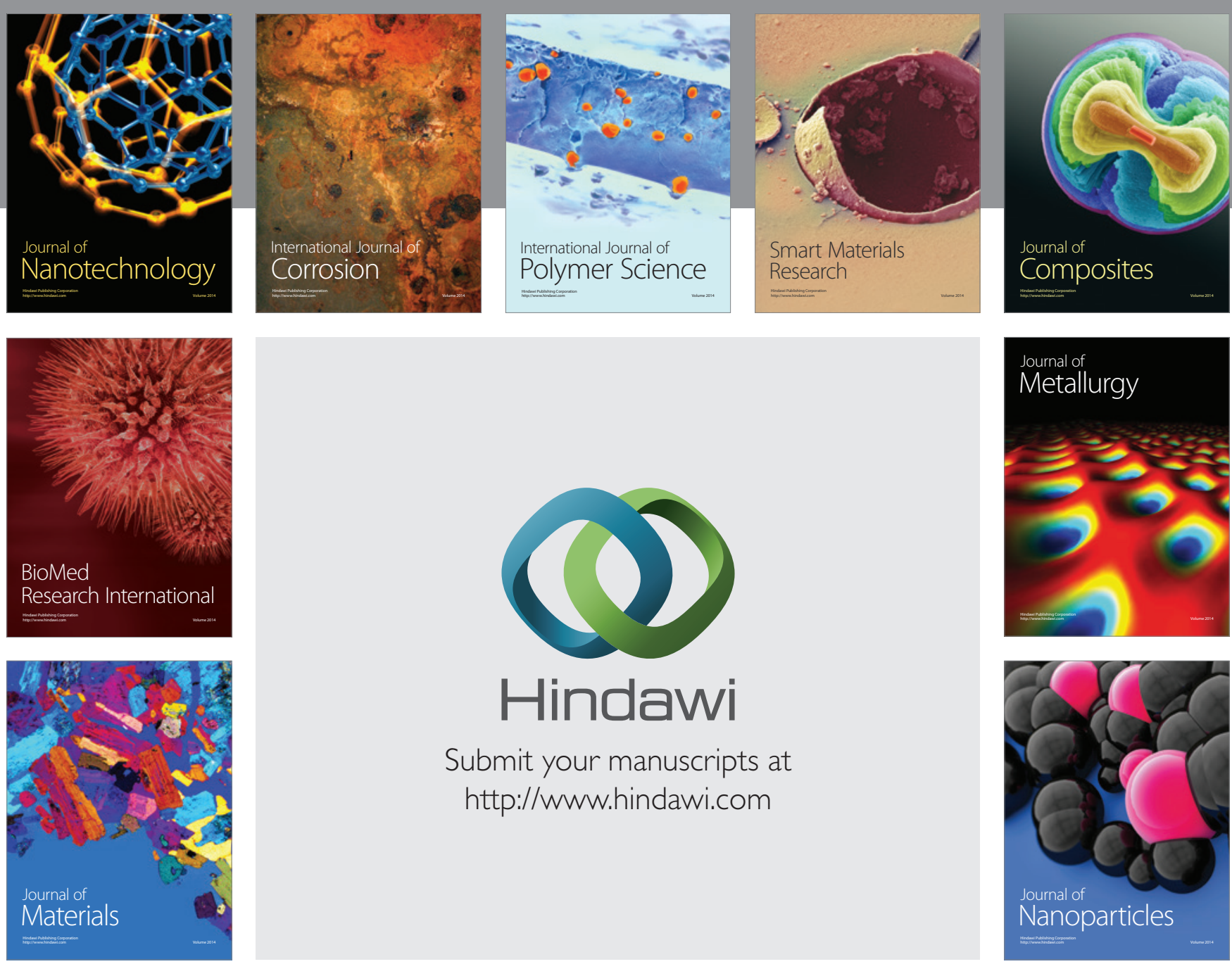

Submit your manuscripts at http://www.hindawi.com
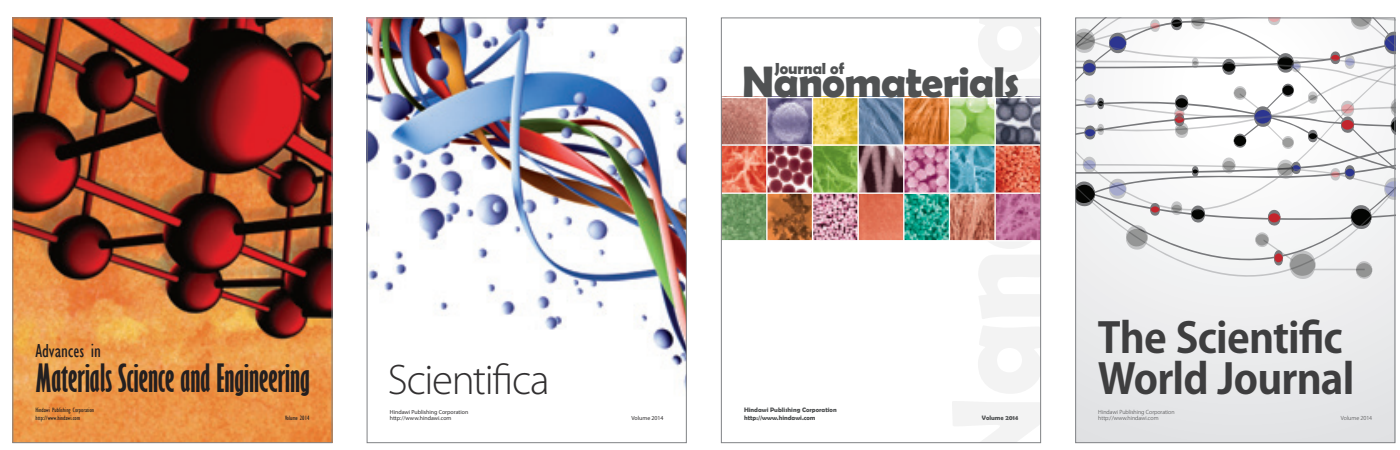

\section{The Scientific World Journal}
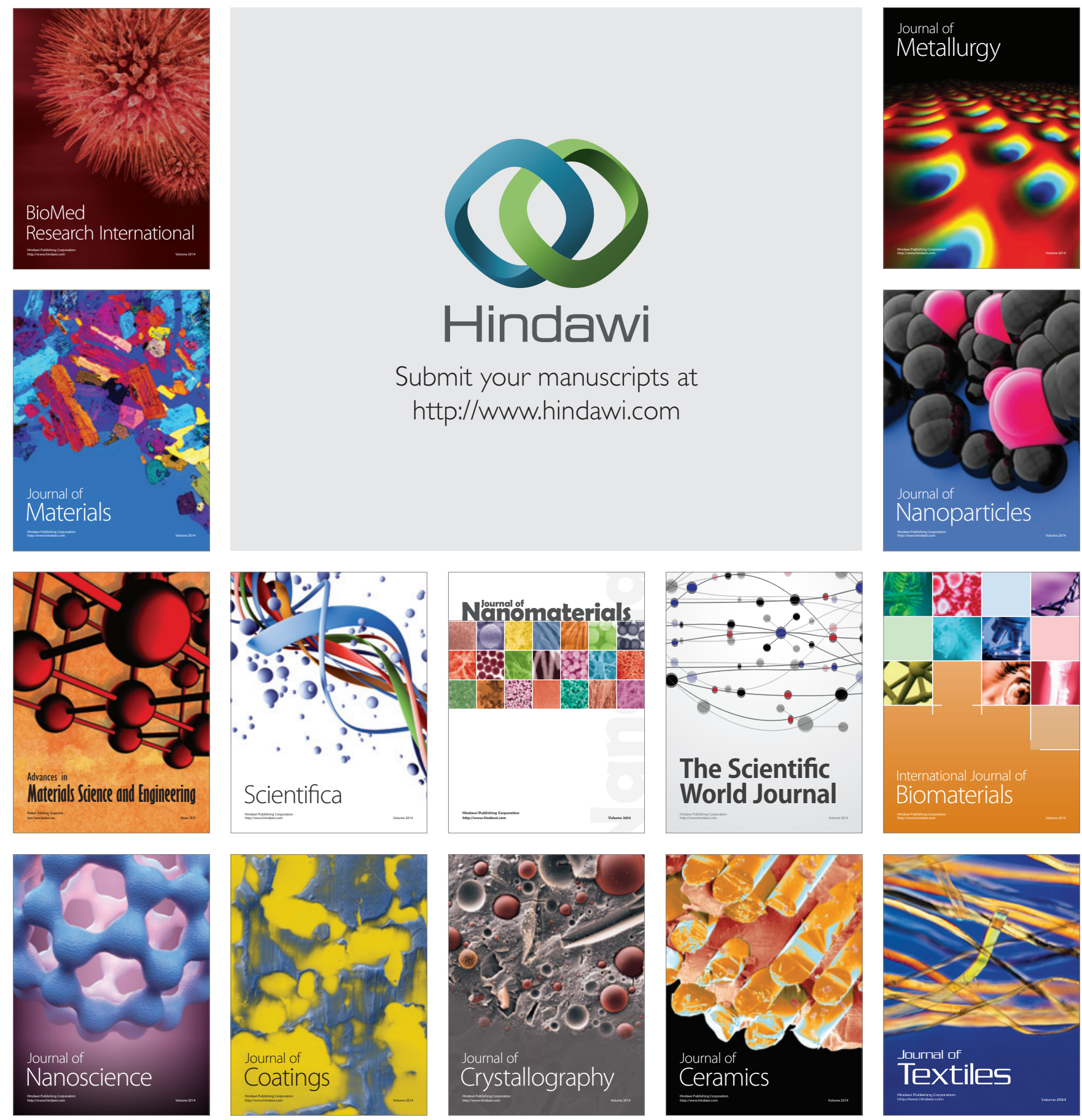